\title{
Bio-efficacy of new long-lasting insecticide-treated bed nets against Anopheles funestus and Anopheles gambiae from central and northern Mozambique
}

\author{
Ana Paula Abílio ${ }^{1}$, Pelágio Marrune ${ }^{2}$, Nilsa de Deus ${ }^{3}$, Francisco Mbofana ${ }^{4}$, Pedro Muianga $^{5}$ \\ and Ayubo Kampango ${ }^{1 *}$
}

\begin{abstract}
Background: Long-lasting insecticide-treated nets (LLINs) are one of the main methods used for controlling malaria transmission in Mozambique. The proliferation of several types of LLINs and the re-emergence of insecticide resistance in the local vector populations poses challenges to the local malaria control programme on selecting suitable insecticide-based vector control products. Therefore, this study evaluated the insecticide susceptibility and bio-efficacy of selected new LLINs against wild populations of Anopheles funestus sensu lato and A. gambiae s.l. from Northern and Central Mozambique. The study also investigated whether the insecticide contents on the LINNs fabrics were within the WHOPES recommended target range.

Methods: The susceptibility of 2-5 day old wild female A. funestus and A. gambiae sensu stricto against the major classes of insecticides used for vector control, viz: deltamethrin (0.05\%), permethrin (0.75\%), propoxur (0.1\%), bendiocarb (0.1\%) and DDT (4\%), was determined using WHO cylinder susceptibility tests. WHO cone bioassays were conducted to determine the bio-efficacy of both pyrethroid-only LLINs (Olyset ${ }^{\circledR}$, Permanet 2.0 ${ }^{\circledR}$, NetProtect ${ }^{\circledR}$ and Interceptor ${ }^{\circledR}$ ) and, Permanet $3.0^{\circledR}$ a combination LLIN against A. funestus s.5, from Balama, Mocuba and Milange districts, respectively. The bio-efficacy of LLINs against the insectary-susceptible A. arabiensis (Durban strain) was assessed, as well. Untreated bed net swatches were used as negative controls. Chemical analyses, by high performance liquid chromatography, were undertaken to assess whether the insecticide contents on the LLINs fabrics fell within recommended target dose ranges. The frequency of $k d r$ gene mutations was determined from a random sample of A. gambiae s.s. from both WHO susceptibility and cone bioassay experiments.

Results: Anopheles funestus from Balama district showed resistance to deltamethrin and possible resistance to permethrin, propoxur and bendiocarb, whilst A. gambiae from Mocuba district was susceptible to deltamethrin, bendiocarb and propoxur. There were no kdr mutants found in the sample of $256 \mathrm{~A}$. gambiae tested. Overall, 186 LLIN swatches were tested. Mosquitoes exposed to Olyset ${ }^{\circledR}$ had the lowest knockdown ( \pm standard error) and mortality rate ( \pm standard error) in all studied sites regardless of vectors species tested. Permanet 3.0 showed the highest bioefficacy independent of vector species tested and level of insecticide resistance detected. All types of LLINs effectively killed susceptible A. arabiensis Durban strain. The insecticide content of Olyset ${ }^{\circledR}$ and Permanet $2.0^{\circledR}$ was higher than the target dose but NetProtect ${ }^{\circledR}$ had a lower insecticide content than the target dose.
\end{abstract}

\footnotetext{
*Correspondence: akampango@gmail.com

${ }^{1}$ Laboratório de Entomologia, Instituto Nacional de Saúde (INS),

Av. Eduardo Mondlane/Salvador Allende, no 1008, C.P. 246 Maputo,

Mozambique

Full list of author information is available at the end of the article
}

\section{Biomed Central}

(c) 2015 Abílio et al. This article is distributed under the terms of the Creative Commons Attribution 4.0 International License (http://creativecommons.org/licenses/by/4.0/), which permits unrestricted use, distribution, and reproduction in any medium, provided you give appropriate credit to the original author(s) and the source, provide a link to the Creative Commons license, and indicate if changes were made. The Creative Commons Public Domain Dedication waiver (http://creativecommons.org/ publicdomain/zero/1.0/) applies to the data made available in this article, unless otherwise stated. 
Conclusion: The study shows evidence of considerable heterogeneity in both insecticide susceptibility and the level of bio-efficacy of commonly available types of LLINs against wild A. funestus and A. gambiae from Balama, Mocuba and Milange districts, located in north and centre of Mozambique. The findings suggest that vector control approaches combining different types of insecticides might help to tackle the apparent problem of pyrethroid resistance in the vector populations from these three sites. Results from bioassays on laboratory-susceptible A. arabiensis strongly suggest that LLINs can offer some protection against susceptible malaria vectors.

Keywords: LLINs, Bio-efficacy, Anopheles funestus, A. gambiae, Insecticide resistance, Insecticide content

\section{Background}

Long-lasting insecticide-treated bed nets (LLINs), often in association with indoor residual spraying (IRS), have for decades contributed to the reduction of malaria burden in sub-Saharan Africa [1, 2]. Notwithstanding recent reductions in morbidity and mortality, due to these interventions the disease remains a major problem of public health in Mozambique. The disease is responsible for nearly $45 \%$ of the all cases observed among hospital outpatients and approximately $56 \%$ of internments in paediatric wards [3]. Despite a decline the rate of mortality of malaria remains high, accounting for approximately $26 \%$ of all hospital deaths [4]. LLINs continue to be the key measure for vector control in rural settings throughout the country and, since the introduction of mass distribution campaigns in 2000, it has been estimated that more than 7.6 million LLINs have been distributed, both by the Ministry of Health and partners [4]. Recently, a proliferation of several brands of LLINs in both rural and city markets has been observed. These largely derive from donations from public, private and civil organisations. Despite being beneficial to the population in needing of protection, an uncontrolled variety of nets might inadvertently, contribute to the development and spread of new foci of pyrethroid resistant strains of the local vector populations. Evaluation of LLINs against local vectors in laboratory and field studies should be performed before mass distribution of any LLIN. Moreover, studies have reported that the chemical contents of some brands of LLIN occasionally differ significantly from the recommended target doses [5]. These findings, emphasize the necessity for scrutiny and careful selection of insecticidal-based control measures since the exposure of local vectors to either sub-lethal or higher doses than that recommended for public health pesticides might potentially exacerbate the problem of insecticide resistance, as shown elsewhere [6, 7].

Anopheles funestus, A. gambiae sensu stricto (s.s.) and $A$. arabiensis are the most important malaria vectors found in Mozambique [8-11], whilst A. merus has been reported as playing secondary role on malaria transmission along the coastal regions [12].

High levels of phenotypic and metabolic resistance against the pyrethroids, deltamethrin, permethrin and alpha-cypermethrin and the carbamates propoxur and bendiocarb, have been reported in A. funestus from southern Mozambique [13]. However, the mosquito remained fully susceptible to DDT and malathion [14]. Resistance to lambda-cyhalothrin, permethrin and bendiocarb was reported among A. funestus from Zambézia Province, in the Central region [15], whereas low levels of pyrethroid and malathion resistance was detected in the provinces located in South (Maputo, Gaza and Inhambane) and Centre (Zambezia and Manica) of the country [16]. Published data on the status of insecticide susceptibility in the vector populations from Northern regions remain limited, notwithstanding, in 2006, Casimiro and colleagues [16] have reported full susceptibility to pyrethroids, carbamates and DDT in the population of $A$. funestus from Pemba city, Cabo Delgado Province; in A. gambiae s.s. and A. arabiensis from Namialo district and Nampula city, respectively, both at Nampula Province. This distribution of the patterns of malaria vector resistance against the major classes of insecticides, suggests that site-based evidence must be obtained to improve the sustainability of vector control programmes, as recommended in the WHO's Global Plans for Insecticide Resistance Management and Vector Control [17]. Therefore, laboratory study was conducted to evaluate the response of malaria vectors from Central and Northern Mozambique to selected types of WHOPESrecommended LLINs. The current status of vector susceptibility to selected insecticides from all major classes of insecticides, currently used for vector control, was also assessed, as well as, the concentration of insecticide on LLINs fabrics. The results are discussed with respect to current malaria control policies in Mozambique.

\section{Methods}

\section{Description of study sites}

The study was undertaken during the dry season, from June to August 2012, in Cabo Delgado (northern region) and Zambezia provinces (central region of Mozambique). In Cabo Delgado province larvae survey were undertaken in Balama district $\left(13^{\circ} 20.914^{\prime} \mathrm{S}, 38^{\circ} 34.183^{\prime} \mathrm{E}\right)$, located in the southern part of the province, whilst in Zambezia larvae were collected in Mocuba $\left(16^{\circ} 51.00^{\prime} \mathrm{S}, 36^{\circ} 59.00^{\prime} \mathrm{E}\right)$ 
and Milange districts $\left(16^{\circ} 5.810^{\prime} \mathrm{S}, \quad 35^{\circ} 46.325^{\prime} \mathrm{E}\right)$ both located in the central and northeast part of Zambézia province, respectively. The three districts are among those having the highest malaria prevalence $(\geq 40 \%)$ in the country [18] with a low level of interventions [19]. Balama district is located at an altitude ranging from 200 to $570 \mathrm{~m}$ above the sea level. The climate is semi-arid with a rainy season from December to March. The mean annual precipitation ranges from 800 to $1200 \mathrm{~mm}$, occasionally reaching a maximum of $1500 \mathrm{~mm}$ in those villages closest to the coast. The monthly air temperatures fluctuate from 20 to $25^{\circ} \mathrm{C}$. The Ruassa river is one of the most important sources of surface water in the district. The district hydrography has been dominated by underground rivers, which sometimes give rise to dispersed water bodies (locally known as Ndabo) due to either manmade excavations or through cracks that reach the surface.

Mocuba district is located at an altitude varying from 200 to $400 \mathrm{~m}$ above sea level. The wet season is from November to February, whilst the dry season ranges from March to October, between which some irregular rainfalls also occur. The mean annual rainfalls varies from 850 to $1300 \mathrm{~mm}$ and the mean monthly air temperature varies from 20 to $27{ }^{\circ} \mathrm{C}$. Licungo and Lugela rivers are the most important sources of permanent water in the district.

Milange district is located at the northeast region of Zambézia province at an altitude varying from 200 to $1000 \mathrm{~m}$ above sea level. The district is boarded to the southeast by Mocuba district. The annual precipitation ranges from 800 to $1400 \mathrm{~mm}$. The rainy season occurs between November and May and the mean monthly air temperature fluctuates from 24 to $26^{\circ} \mathrm{C}$.

In all three districts, during the wet season, the mean relative humidity varies from 60 to $80 \%$.

The people residing in the study sites are mainly subsistence farmers who grow crops such as rice, maize, beans, and manioc and cotton on the banks of small streams or rivers. Most houses are built of bamboo reinforced with mud and covered by either thatched roofs or corrugated zinc sheets. Anopheles funestus is the most common malaria vector in Balama and Milange district whilst $A$. gambiae sensu lato (s.l.) is the most common in Mocuba district. Other Anopheles and culicinae species, such as A. tenebrosus, A. pharoensis, Mansonia spp. and Culex spp. occur also.

\section{Mosquito collection}

Mosquito larvae were collected in both known and potential breeding sites located along the main rivers and water collections usually found in the three districts. Larvae were collected using pipettes, dippers and bowls, depending on whether the breeding site was small or large one [20].

In Balama district larvae were collected in four breeding sites; two situated in Kwekwe village (breeding site 1: $13^{\circ} 45.567^{\prime} \mathrm{S} ; 38^{\circ} 24.767^{\prime} \mathrm{E}$ and breeding site $2: 13^{\circ} 57.139^{\prime} \mathrm{S}$; $\left.38^{\circ} 23.314^{\prime} \mathrm{E}\right)$ and the other two in Mavala $\left(13^{\circ} 11.776^{\prime} \mathrm{S}\right.$; $\left.38^{\circ} 18.345^{\prime} \mathrm{E}\right)$ and Impiri $\left(13^{\circ} 19.861^{\prime} \mathrm{S} ; 38^{\circ} 15.684^{\prime} \mathrm{E}\right)$ villages. In Mocuba district larvae were collected in Mocuba city $\left(16^{\circ} 50.997^{\prime} \mathrm{S} ; 36^{\circ} 59.000^{\prime} \mathrm{E}\right)$, whilst in Milange district collections were carried out in Majaua $\left(16^{\circ} 16.919^{\prime} \mathrm{S}\right.$; $\left.35^{\circ} 26.998^{\prime} \mathrm{E}\right)$ and Molumbo $\left(15^{\circ} 47.301^{\prime} \mathrm{S} ; 35^{\circ} 59.741^{\prime} \mathrm{E}\right)$ villages (Fig. 1).

Larvae collected in Balama district were brought to the insectary located in Pemba city, the capital of Cabo Delgado province, whilst those collected in Mocuba and Milange districts were brought to the insectary located in the Quelimane city, capital of Zambezia province. Larvae were transferred into bowls and held in the insectary at room temperature and humidity of $25.1 \pm 2{ }^{\circ} \mathrm{C}$ and $80 \pm 5.4 \%$, respectively, until eclosion to adult mosquitoes. Newly emerged adult females were sorted and identified morphologically according to available taxonomic keys [21]. Anopheles funestus and A. gambiae s.l. were kept in separate cages. Morphological identification was posteriorly confirmed by PCR analysis, for members of $A$. funestus group [22] and the A. gambiae complex [23].

\section{Insecticide susceptibility tests}

WHO susceptibility tests [24] were conducted to determine the susceptibility of collected vectors against permethrin $(0.75 \%)$, deltamethrin $(0.05 \%)$, bendiocarb $(0.1 \%)$, propoxur $(0.1 \%)$ and DDT (4\%). Only insecticides used to treat LLINs, as well as, those insecticides that have already been used or are currently being used for IRS. Twenty-five sugar-fed, 2-5 years old, females were transferred into testing cylinders containing papers impregnated with insecticide. The knockdown rate of mosquito exposed to the insecticides was recorded each $10 \mathrm{~min}$, over $1 \mathrm{~h}$ exposure-period. At least four replicates were obtained for each type of insecticide tested, giving a minimum of 100 mosquitoes per insecticide. Concurrently, 50 mosquitoes ( 25 per cylinder) were exposed to papers impregnated with mineral oil to act as negative controls. Mosquitoes were later transferred into recovery cups and provided with cotton wool soaked in $10 \%$ glucose solution and the final mortality was recorded $24 \mathrm{~h}$ later. If the mortality rate in the control cups was between 5 and $20 \%$, the final mortality rate was adjusted according to Abbott's formula. When the mortality rate in the controls was $>20 \%$, the test was discarded. Vectors were considered as being susceptible to a given insecticide if mortality rate was $\geq 98 \%$, resistant if mortality $<80 \%$ or possibly resistant if mortality was between 80 


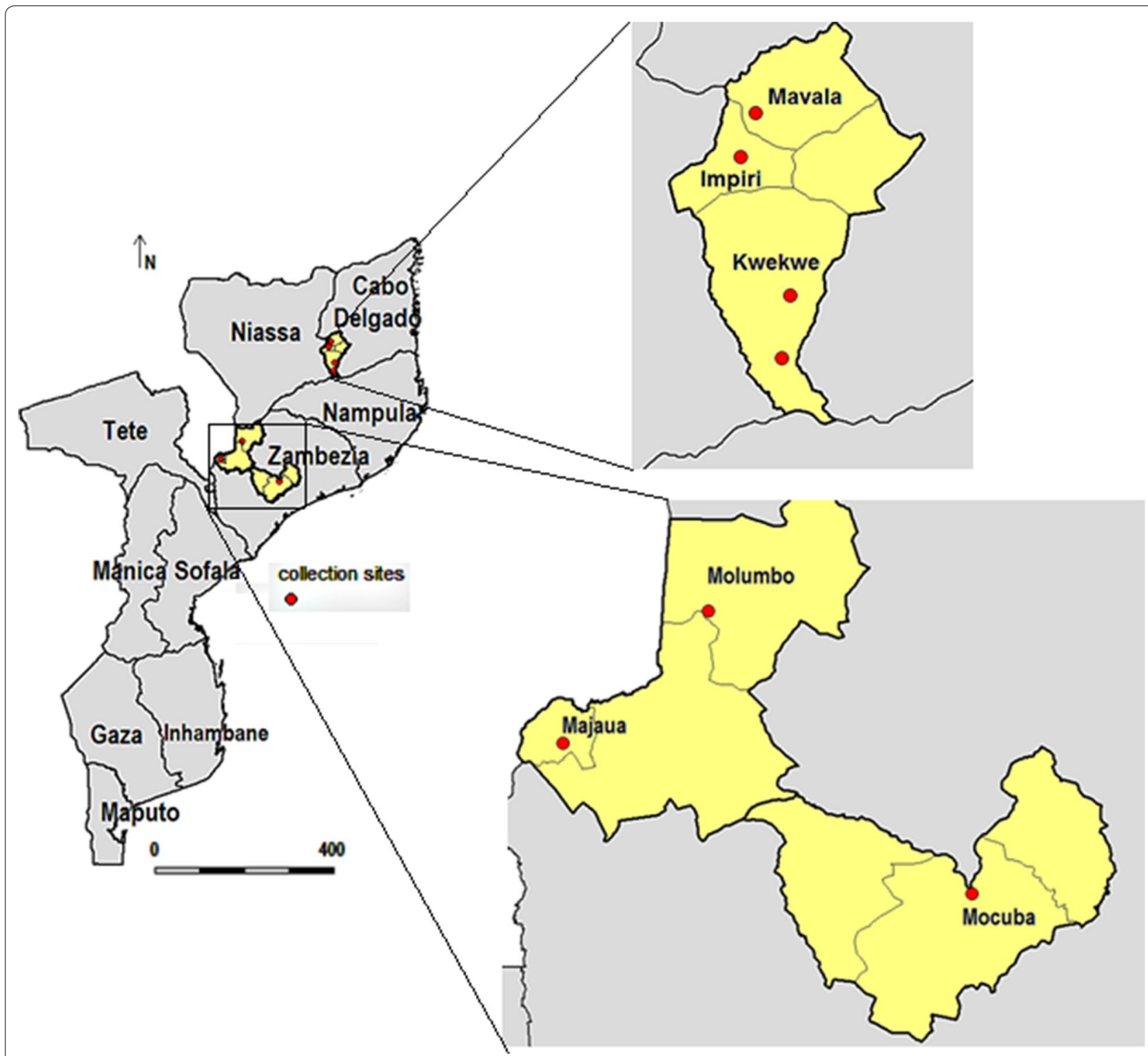

Fig. 1 Map of Mozambique showing the geographical location of the sites where Anopheles funestus (Balama and Mocuba district) and Anopheles gambiae (Milange district) larvae were collected. In Balama district, larvae were collected in Malava, Impiri and Kwekwe villages; in Milange district larvae were collected in Majaua and Molumbo villages and in Mocuba district larvae were collected in Mocuba town

and $98 \%$. Mosquitoes from this test were later stored in tubes continuing silica gel and, a random sample of 194 (94 A. funestus and 100 A. gambiae s.l) mosquitoes was taken for molecular identification of vector complexes members [23]. Those specimens identified as either $A$. gambiae or A. arabiensis were later screened for the presence of target-site resistance $k d r$ (East and West) mutations by allele-specific polymerase chain reaction, as suggested by Martin-Torre et al. [25] and Ranson et al. [26]. These mutations have often been found associated with pyrethroid/DDT cross-resistance in populations of
A. gambiae s.s., A. arabiensis and other vectors [27] but not reported in members of the A. funestus group [28].

\section{Extraction and preparation of LLINs sub-samples}

The main goal was to determine the bio-efficacy and insecticide content of LLINs available in Mozambique. Five types of rectangular LLINs were investigated namely: pyrethroid-only Olyset ${ }^{\circledR}$ (polyethylene fabric incorporated with $20 \mathrm{~g} / \mathrm{kg}$ of permethrin), Permanet $2.0^{\circledR}$ (polyester fabric coated with $55 \mathrm{mg} / \mathrm{m}^{2}$ of deltamethrin), NetProtect ${ }^{\circledR}$ (polyethylene incorporated with 
$1.8 \mathrm{~g} / \mathrm{kg}$ of deltamethrin), Interceptor ${ }^{\circledR}$ (polyester coated with $200 \mathrm{mg} / \mathrm{m}^{2}$ of alpha-cypermethrin) and combination LLINs Permanet $3.0^{\circledR}$. Permanet $3.0^{\circledR}$ is made mainly of polyethylene fabric incorporated with $2.1 \mathrm{~g} /$ $\mathrm{kg} \pm 25 \%$ of deltamethrin alone (on the upper sides) and $4 \mathrm{~g} / \mathrm{kg} \pm 25 \%$ of deltamethrin combined with $25 \mathrm{~g} / \mathrm{kg}$ of a synergist piperonil butoxide (PBO) on the roof and coated with $2.8 \mathrm{~g} / \mathrm{kg} \pm 25 \%$ of deltamethrin on the lower sides, also called borders. The lower sides are reinforced with polyester fabric $[29,30]$. The PBO acts by enhanced the penetration rate of the insecticide deltamethrin through the insect cuticle inhibiting, thereby, the insects defence mechanisms, particularly the effect of enzymes P450 monooxygenases [31]. Olyset ${ }^{\circledR}$ and Permanet $2.0^{\circledR}$ are usually distributed as part of either mass or antenatal distribution campaigns whilst NetProtect ${ }^{\circledR}$ and Interceptor $^{\circledR}$ are available for purchase at some local markets. Therefore, Olyset ${ }^{\circledR}$ and Permanet $2.0^{\circledR}$ were obtained through public and private partners of the Mozambique Ministry of Health, currently supporting the National Malaria Control Programme (NMCP) whereas, NetProtect ${ }^{\circledR}$ and Interceptor ${ }^{\circledR}$ were obtained by convenience and availability from the local markets. The hygiene conditions in the particular place of selling, as well as, the storage conditions of the LLINs was carefully inspected before proceeding with the purchasing of the nets. The combination LLINs PermaNet $3.0^{\circledR}$ were kindly donated by Vestegaard Frandsen Ltd. All LLINs were carefully inspected to verify the physical integrity of the packet, manufacturing date and batch number.

Three samples of each LLIN were obtained. For each pyrethroid-only LLIN, (viz: Olyset ${ }^{\circledR}$, Permanet $2.0^{\circledR}$, NetProtect $^{\circledR}$ and Interceptor $\left.{ }^{\circledR}\right)$, three $30 \times 30 \mathrm{~cm}$ swatches from each long side and from the roof of the net were taken, making a total of 9 ( $3 \times 3$ LLINs) swatches per type of LLINs, whilst for the combination LLIN (PermaNet $3.0^{\circledR}$ ), two swatches from the long lower sides (borders), two from the long upper sides and one from the roof were taken, giving a total of 15 ( $5 \times 3$ LLINs $)$ samples. Individual samples were wrapped in aluminium foil and placed inside plastic labelled zip lock bags to prevent possible cross-contamination between sub-samples.

\section{WHO cone bioassay}

WHO Cone bioassays were conducted with 2-5 day old sugar-fed females following standard WHO procedures [32]. Four cones, each containing five mosquitoes, were put in contact to $30 \times 30 \mathrm{~cm}$ swatches taken from the sides and roof of pyrethroid-only LLINs (Olyset ${ }^{\circledR}$, Permanet $2.0^{\circledR}$, NetProtect ${ }^{\circledR}$ and Interceptor ${ }^{\circledR}$ ) and combination LLIN (PermaNet $3 \cdot 0^{\circledR}$ ). Mosquitoes were exposed for $3 \mathrm{~min}$ after which were transferred into recovery paper cups and provided with cotton wool soaked in a solution of $10 \%$ glucose. Each swatch was tested twice, giving a total of 40 mosquitoes tested per swatch, i.e., 20 mosquitoes per 2 replicates. Mosquito knockdown rate (KD) was recorded every $30 \mathrm{~min}$ during a 1-h post-exposure period (KD 60) and the final mortality rate (MT) was determined $24 \mathrm{~h}$ post-exposure. The mortality rate was corrected using Abbott's formula when mortality in the control was 5-20\%. Otherwise, if mortality rate in the control tube was $>20 \%$, the bioassay round was discarded and a new test was conducted. A total of 360 mosquitoes (40 mosquitoes $\times 3$ swatches $\times 3$ LLINs samples) were used to test each type of pyrethroid-only LLIN whilst, 600 (40 mosquitoes $\times 5$ swatches $\times 3$ LLINs samples) were used to test Permanet $3.0^{\circledR}$. A random sample of 477 (321 A. funestus and 156 A. gambiae s.l.) mosquitoes from this assay was used for molecular identification of vector complexes members and determination of $k d r$ (WestEast) resistance allele mutations, as above indicated [25]. Cone bioassays were also conducted against a susceptible colony of $A$. arabiensis (Durban strain) maintained at the entomology laboratory of the National Institute of Health (INS) in Maputo city. These tests were conducted at a room temperature and relative humidity of $25 \pm 2{ }^{\circ} \mathrm{C}$ and $80 \pm 5 \%$, respectively. The susceptibility status of the colony against the classes of insecticides commonly used for vector control has been assessed every 6 months. Sub-samples from an untreated bed-net were used concurrently as negative controls of the bioassays.

\section{Chemical analysis for insecticide contents}

Additional samples of netting from the sides of pyrethroid-only LLINs and Permanet $3.0^{\circledR}$ were collected for chemical analysis to determine if the insecticide content of the fabric was within the recommended target range. The insecticide content was determined through High Performance Liquid Chromatography (HPLC) using protocols developed by the Collaborative International Pesticides Analytical Council (CIPA) [33, 34]. Thus, deltamethrin was extracted in a mixture of iso-octane and 1,4-dioxane solution and the concentration was determined by normal-phase HPLC using dipropyl phthalate as internal standard and detection at $236 \mathrm{~nm}$, whilst, alpha-cypermethrin was extracted with n-hexane and 1, 4-dioxane $(95: 5 \mathrm{v} / \mathrm{v})$, shaken, sonicated and later filtered on a $0.45 \mathrm{~mm}$ Teflon membrane. Permethrin and piperonil-butoxide ( $\mathrm{PBO}$ ) were both extracted in the presence of hot xylene followed by drying, reconstitution and filtrations process before the final concentration was determined by HPLC. Insecticide concentration (IC) was calculated using the formula $(\mathrm{An} / \mathrm{As}) \times \mathrm{Cs} \times(\mathrm{Vn} / \mathrm{ms})$, where $\mathrm{An}$ is the area of the insecticide peak in net sample, As is average area of the insecticide peak in the working standards (from a single point calibration prepared at 
the target concentration), Cs is average concentration of the working standards $(\mathrm{mg} / \mathrm{ml}), \mathrm{Vn}$ is volume of sample solution (100 ml) and $\mathrm{ms}$ is mass of net sample [35].

\section{Statistical data analysis}

The significance of the differences between knockdown (KD 60) and mortality rates of mosquitoes exposed to different types of LLIN were analysed by Generalized Linear Mixed Models (GLIMM) using binomial error distribution and logit link function [36]. Initially, GLIMM tests were applied using lme4 v. 1.1-7 package [37], the type of LLIN was considered as fixed factor, whilst the sides and roof of it was considered as a random factor nested within each bed net type, so as to account for any possible non-constant variability of knockdown and mortality rates between the side of LLINs and any possible correlations between repeated measures taken from the same swatch. Subsequently, the fitted models for each study site and species tested were used to determine the significance of difference of KD 60 and mortality rate between the types of LLINs using the package multcomp v. 1.3-7 [38]. The Tukey HSD test was applied to assess the significance of the differences. The $p$-values estimated by the Tukey HSD test was adjusted to account for multiplicity and correlation between statistics using the Westfall truncated closed test procedure, implemented also with multcomp v. 1.3-7 [39]. Probit regression analysis was applied to mortality rates from the susceptibility tests to estimate the median exposure time necessary to kill $50 \%$ $\left(\mathrm{KDT}_{50}\right)$ and $95 \%\left(\mathrm{KDT}_{95}\right)$ of the vector populations when exposed to each class of insecticides tested, using the package drc [38]. All statistical analysis were performed using R v. 3.1.2 [40].

\section{Ethical considerations}

The study received ethical approval by the National Committee of Bioethics of the Mozambique Ministry of Health, under the registration number 06/CNBS/12.

\section{Results}

\section{Vector populations}

1680 A. funestus from Balama and 1670 Mocuba districts and 1720 A. gambiae s.l. from Milange district were used to perform cone bioassays. 10 data points of Permanet 3.0 from Milange district were missing. Additionally, 500 A. funestus and $400 \mathrm{~A}$. gambiae were used to undertake the susceptibility tests against Propoxur, Deltamethrin, Permethrin, Bendiocarb and DDT.

All 415 members of the $A$. funestus group analysed by PCR were A. funestus s.s and all 256 A. gambiae s.l. were A. gambiae s.s, $\mathrm{S}$ form. Therefore we presume that these were the only two vector species in the study.

\section{Insecticide susceptibility}

The knockdown rates of $A$. funestus s.s. and A. gambiae s.s. (henceforth $A$. funestus and $A$. gambiae) exposed to five selected insecticides are showed in Fig. 2a, b, respectively. The probability of an insect being knocked down during the first $30 \mathrm{~min}$ of exposure varied from 0 to $46 \%$ (in A. funestus) and 0 to $50 \%$ (in A. gambiae), suggesting that a high frequency of resistant strains in the two vector populations. These results were later corroborated by the estimates of the median time (in minutes) required to kill $50 \%\left[\mathrm{KDT}_{50}( \pm 95 \% \mathrm{CI})\right]$ and $95 \%\left[\mathrm{KDT}_{95}( \pm 95 \% \mathrm{CI})\right]$ of the vectors populations when exposed to the same insecticides (Tables 1, 2). There was no expressive difference between these estimates for either species. The smallest $\mathrm{KDT}_{50}$ estimate for A. funestus was observed when mosquitoes were exposed to propoxur [29.37 (27.17-31.58)], whilst the smallest $\mathrm{KDT}_{95}$ was observed against bendiocarb [58.84 (53.18-64.50)]. The shortest $\mathrm{KDT}_{50}$ and $\mathrm{KDT}_{95}$, in $A$. gambiae was observed with deltamethrin [31.61 (29.81-33.41)], bendiocarb [33.28 (31.55-35.01)] and propuxor [34.9 (33.24-36.61)] whilst, the shortest $\mathrm{KDT}_{95}$ estimate was 62.29 (56.32-68.26) obtained against bendiocarb and propoxur, respectively.

In Balama district, the mortality rates of $A$. funestus recorded $24 \mathrm{~h}$ post-exposure, suggest that it might be resistance to virtually all four types of insecticides tested (Table 1). In Mocuba, on the other hand, results suggested that $A$. gambiae might be resistant to permethrin, propoxur and DDT and, susceptible to deltamethrin and bendiocarb (Table 2). However, molecular analysis failed to reveal the presence of $\mathrm{kdr}$ gene mutant alleles in random sample of 250 specimens of A. gambiae tested. Susceptibility tests were not performed on mosquitoes from Milange district due to the low number of mosquitoes collected.

\section{Bio-efficacy of LLINs against wild-caught vector populations}

135 LLINs swatches were obtained, 90 from pyrethroidonly LLINs and 45 from combination Permanet $3.0^{\circledR} .84$ swatches were tested against $A$. funestus from Balama (42/135) and Mocuba (42/135) districts and 51/135 against $A$. gambiae from Milange district, respectively the knockdown (KD 60) and mortality rates of the two species exposed to the five types of LLINs are depicted on Table 3 and Fig. 3. There was a significant difference in both knockdown $(\mathrm{F}=151.52, P<0.0001)$ and mortality rates $(\mathrm{F}=181.74, P<0.0001)$ of mosquitoes exposed to LLINs. In addition, there was also a significant correlation between the knockdown rate and mortality rate $\left(\mathrm{R}^{2}=0.857, P<0.0001\right)$, when the data were stratified by species and study sites, indicating that previous exposure of mosquitoes to insecticides on bed nets explained 

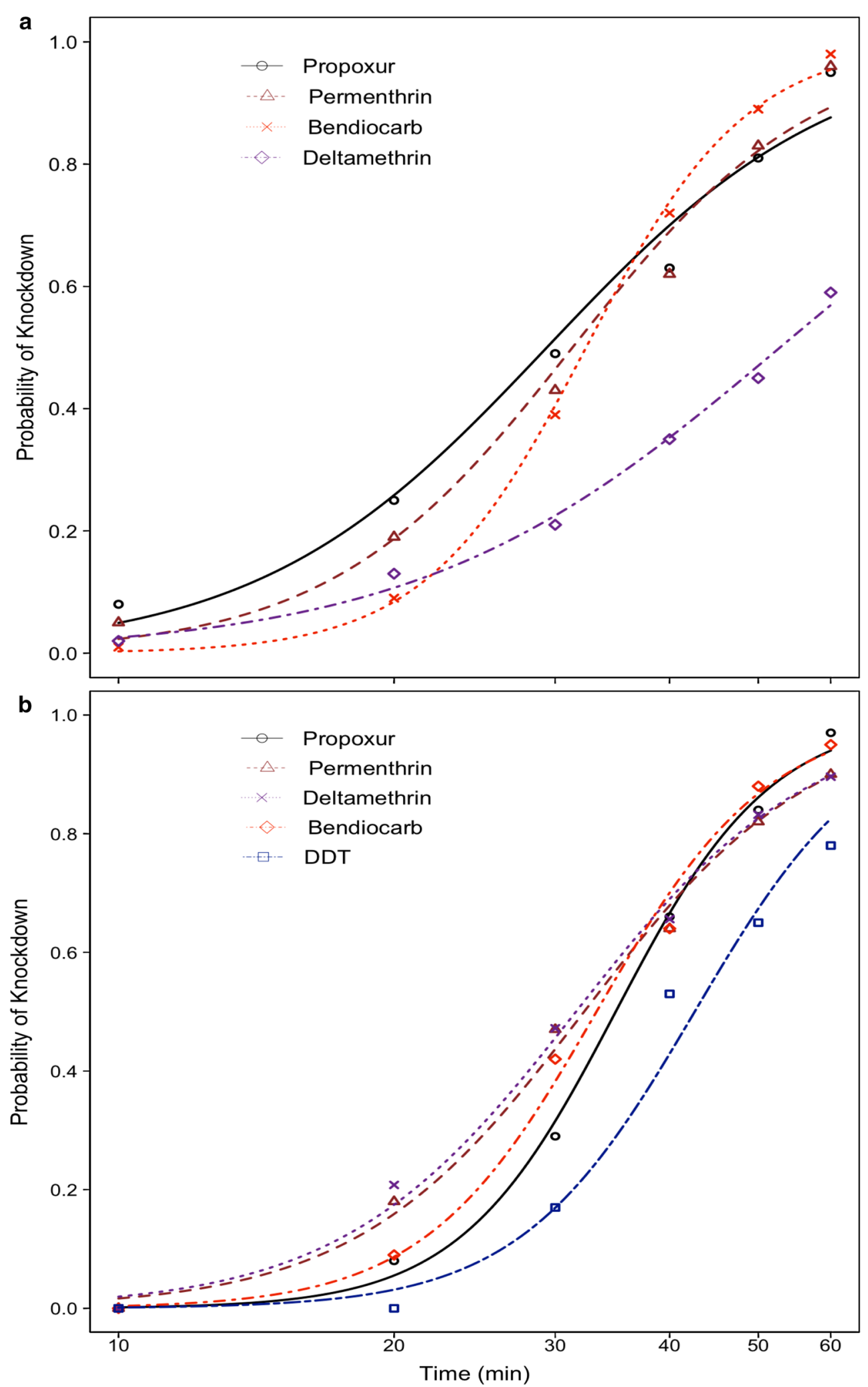

Fig. 2 Response curves showing the probability of knockdown of Anopheles funestus $\mathbf{a}$ from Balama distric and Anopheles gambiae s.s $\mathbf{b}$ from Mocuba district exposed to selected types of insecticides over 60 min exposure-time 
Table 1 Mortality rate of Anopheles funestus from Balama district exposed to four types of insecticides and, the estimated median time (in minutes) required to kill $50 \%\left(\mathrm{KDT}_{50} \pm 95 \% \mathrm{Cl}\right.$ ) and $95 \%\left(\mathrm{KDT}_{95} \pm 95 \% \mathrm{Cl}\right)$ of the vector population when exposed to the same insecticides

\begin{tabular}{|c|c|c|c|c|}
\hline Insecticide & $\begin{array}{l}\text { Mosquito } \\
\text { tested }\end{array}$ & $\mathrm{KDT}_{50}( \pm 95 \% \mathrm{Cl})$ & $\mathrm{KDT}_{95}( \pm 95 \% \mathrm{Cl})$ & Mortality rate \\
\hline Deltamethrin (0.05 \%) & 100 & $52.81(47.11-58.51)$ & $203.07(127.33-278.81)$ & 85 \\
\hline Permethrin (0.75 \%) & 100 & $31.33(29.28-33.38)$ & 77.08 (65.88-88.29) & 97 \\
\hline Bendiocarb (0.1%) & 100 & $32.42(30.78-34.06)$ & $58.84(53.18-64.50)$ & 92 \\
\hline Propoxur (0.1 \%) & 100 & $29.37(27.17-31.58)$ & $85.92(70.97-100.88)$ & 94 \\
\hline
\end{tabular}

Table 2 Mortality rate of Anopheles gambiae from Mocuba district exposed to five types of insecticides and, the estimated median time (in minutes) required to kill $50 \%\left(\mathrm{KDT}_{50} \pm 95 \% \mathrm{Cl}\right.$ ) and $95 \%\left(\mathrm{KDT}_{95} \pm 95 \% \mathrm{Cl}\right.$ ) of the vector population when exposed to the same insecticides

\begin{tabular}{lllll}
\hline Insecticide & $\begin{array}{l}\text { Mosquito } \\
\text { tested }\end{array}$ & $\mathbf{K D T}_{\mathbf{5 0}}(\mathbf{9 5} \% \mathbf{C l})$ & $\mathbf{K D T}_{\mathbf{9 5}}(\mathbf{9 5} \mathbf{\%} \mathbf{C l})$ & Mortality rate \\
\hline Deltamethrin $(0.05 \%)$ & 125 & $31.61(29.81-33.41)$ & $75.24(65.82-84.65)$ & 99.2 \\
Permethrin $(0.75 \%)$ & 100 & $32.26(30.25-34.27)$ & $75.11(64.80-85.42)$ & 97 \\
Bendiocarb (0.1 \%) & 100 & $33.28(31.55-35.01)$ & $62.29(56.32-68.26)$ & 99 \\
Propoxur (0.1 \%) & 100 & $34.9(33.24-36.61)$ & $62.29(56.33-68.26)$ & 98 \\
DDT (4\%) & 100 & $42.6(40.51-44.69)$ & $81.59(71.40-91.77)$ & 97 \\
\hline
\end{tabular}

Table 3 Knockdown (KD $60 \pm$ standard error) and mortality ( \pm standard error) rates of A. funestus (Balama and Mocuba district) and $A$. gambiae from Milange district tested against five brands of Long-lasting insecticide-treated bed nets (LLINs)

\begin{tabular}{|c|c|c|c|c|c|}
\hline \multirow[t]{2}{*}{ LLINs } & \multirow{2}{*}{$\begin{array}{l}\text { Mosquito tested } \\
\text { per site }\end{array}$} & \multirow[t]{2}{*}{ Bio-efficacy indexes } & \multicolumn{3}{|l|}{ Study districts } \\
\hline & & & Balama (A. funestus) & Mocuba ( $A$. funestus) & Milange (A. gambiae) \\
\hline \multirow[t]{2}{*}{ Olyset } & 360 & KD 60 (土se) & $35.55( \pm 3.15)$ & $49.14( \pm 2.47)$ & $57.5( \pm 2.71)$ \\
\hline & & Mortality rate ( \pm se) & $20.9( \pm 2.34)$ & $38.07( \pm 3.07)$ & $40.77( \pm 2.82)$ \\
\hline \multirow[t]{2}{*}{ Permanet 2.0} & 360 & KD 60 (土se) & $69.72( \pm 3.40)$ & $78.61( \pm 2.18)$ & $91.25( \pm 1.30)$ \\
\hline & & Mortality rate $( \pm s e)$ & $60.48( \pm 3.64)$ & $81.94( \pm 2.32)$ & $89.65( \pm 1.65)$ \\
\hline \multirow[t]{2}{*}{ Permanet 3.0} & 600 & KD 60 (土se) & $93.33( \pm 1.12)$ & $85.16( \pm 1.43)$ & $99.64( \pm 0.36)$ \\
\hline & & Mortality rate ( \pm se) & $85.5( \pm 2.09)$ & $90.16( \pm 1.27)$ & $98.92( \pm 0.61)$ \\
\hline \multirow[t]{2}{*}{ NetProtect } & 360 & KD 60 (土se) & $61.38( \pm 2.79)$ & $62.22( \pm 2.52)$ & $83.88( \pm 1.61)$ \\
\hline & & Mortality rate ( \pm se) & $23.95( \pm 2.34)$ & $63.61( \pm 2.95)$ & $78.87( \pm 3.56)$ \\
\hline \multirow[t]{2}{*}{ Interceptor } & 360 & KD 60 (土se) & - & - & $80.83( \pm 1.87)$ \\
\hline & & Mortality rate $( \pm s e)$ & - & - & $77.84( \pm 2.16)$ \\
\hline
\end{tabular}

(-) Not tested

Highlighted cell indicates where significant difference between knockdown and mortality rate was found at $5 \%$ significance level

$85.7 \%$ of the total variation of mortality rates recorded $24 \mathrm{~h}$ post-exposure. Therefore, further statistical analyses were mainly focused on mortality rates as an indicator of bio-efficacy.

In general, the pyrethroid-only Olyset ${ }^{\circledR}$ (permethrin incorporated) showed the lowest bio-efficacy (mean \pm standard error) against $A$. funestus from Balama $(20.9 \pm 2.34)$ and Mocuba $(38.07 \pm 3.07)$ and A. gambiae from Milange $(40.77 \pm 2.82)$ when compared to the same vectors exposed to other types of LLINs (Table 3). The highest bio-efficacy was observed with deltamethrin coated (Permanet $2.0^{\circledR}$ ), deltamethrin incorporated $\left(\right.$ NetProtect $\left.{ }^{\circledR}\right)$ and deltametrin incorporated/coated plus piperonyl-butoxide (PBO) incorporated Permanet 3.0 (Table 3). The LLIN Interceptor ${ }^{\circledR}$ (alpha-cypermetrin coated) was only tested against $A$. gambiae from Milange district. The mortality rate ( \pm standard error) of $A$. gambiae exposed to Interceptor ${ }^{\circledR}$ was $77.84 \pm 2.16$. This was 


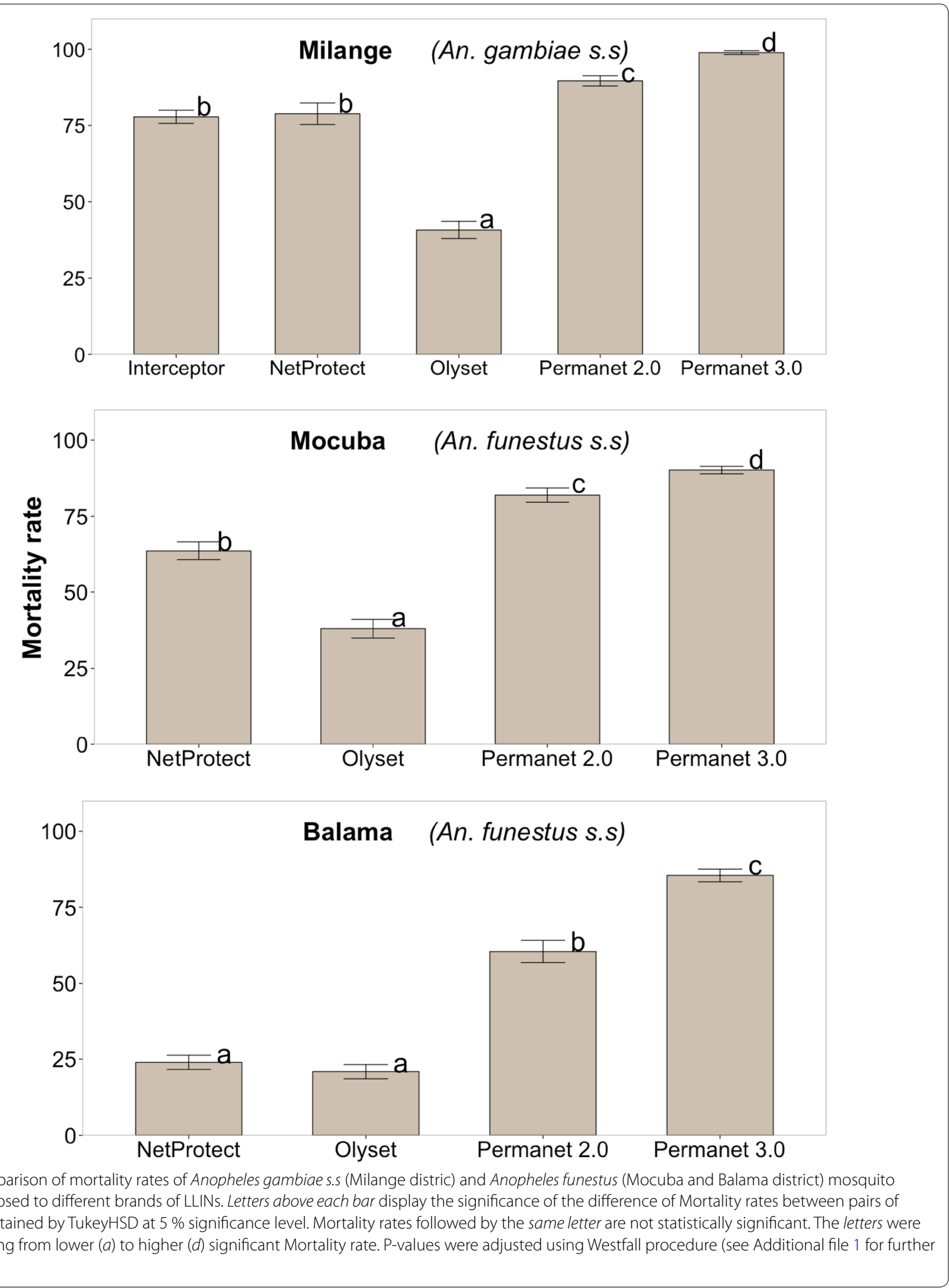


similar to that obtained with Netprotect ${ }^{\circledR}(78.87 \pm 3.56$; $P=0.839$ ). The mortality of $A$. funestus from Balama district exposed to Netprotect ${ }^{\circledR}(23.95 \pm 2.34)$ and Olyset ${ }^{\circledR}$ $(20.9 \pm 2.34 ; P=0.129)$ did not differ significantly (see Fig. 3; Additional file 1, for further details).

Results of mortality rates of mosquitoes exposed to Permanet $3.0^{\circledR}$ were stratified by site of the bed-net, namely, lower side (border), upper side and roof (Fig. 4). The mortality rate of $A$. funestus from Balama district exposed to roof sub-samples was significantly higher than of those exposed to samples from lower sides [Estimated difference \pm standard error $(\mathrm{se})=18.54 \pm 5.47 ; P=0.003]$ and upper sides [Estimated difference $\pm \mathrm{se}=17.71 \pm 5.46$; $P=0.003$ ]. A similar result was obtained with $A$. funestus from Mocuba district, i.e. estimated difference $( \pm$ se) roof vs. lower side $(11.88 \pm 3.31 ; P=0.0013)$; roof vs. upper side $(10.63 \pm 3.31 ; P=0.0017)$. There was no significant difference of mortality rates of $A$. gambiae from Milange district, exposed to swatches from either sides of Permanet 3.0 ${ }^{\circledR}$ (Fig. 4; Table 4; Additional file 2).

\section{Bio-efficacy against colony susceptible vectors}

A total of 51 swatches (36 from pyrethroid-only LLINs and 15 from combination Permanet $3.0^{\circledR}$ ) were tested against the colony of susceptible $A$. arabiensis (Durban strain). The knockdown and mortality rates from this bioassay indicate that all type of LLINs performed well against this mosquito (Table 5). The mortality rate ( \pm standard error) varied from $90.36 \pm 1.34 \%$ to $100 \pm 0.00 \%$ when mosquitoes were exposed to Olyset ${ }^{\circledR}$, Permanet $2.0^{\circledR}$ and Permanet $3.0^{\circledR}$, respectively. Comparisons between the mortality rates of wild-caught $A$. funestus and A. gambiae (see Table 4) and the A. arabiensis colony (Table 5) indicated that the mortality rate of the $A$. arabiensis exposed to both Olyset ${ }^{\circledR}$ and NetProtect ${ }^{\circledR}$ was two to four times higher than the rates obtained with $A$. funestus from Balama and Mocuba district and A. gambiae from Milange district (see Additional file 3). There was no expressive difference of the ratios between the mortality rates of susceptible and wild-caught mosquitoes exposed to Permanet $2.0^{\circledR}$, Permanet $3.0^{\circledR}$ and Interceptor $^{\circledR}$ (Additional file 3).

\section{Insecticide contents on the LLINs}

Fifty-one swatches were assessed for insecticide concentration, 36 from pyrethroid-only LLINs and 15 from combination Permanet $3.0^{\circledR}$. The results indicated that, the insecticide concentration on the swatches from sides $(1.0 \mathrm{~g} / \mathrm{kg})$ and roof $(1.0 \mathrm{~g} / \mathrm{kg})$ of NetProtect ${ }^{\circledR}$ were below the target dose range $(1.8 \mathrm{~g} / \mathrm{kg})$ whereas, the sides $(23.2 \mathrm{~g} /$ $\mathrm{kg})$ and roof $(23.6 \mathrm{~g} / \mathrm{kg})$ of Olyset ${ }^{\circledR}$ and roof $\left(73.2 \mathrm{mg} / \mathrm{m}^{2}\right)$ of Permanet $2.0^{\circledR}$ had insecticide content above those specified by manufacturers (Table 6).

\section{Discussion}

\section{Vector susceptibility to insecticides}

The results from WHO susceptibility tests indicate that the A. funestus population from Balama district, Cabo Delgado Province, has possibly became resistant to all the four types of insecticides tested two of which were pyrethroids and two carbamates viz: deltamethrin (0.05\%), permethrin $(0.75 \%)$, bendiocarb $(0.1 \%)$ and propoxur $(0.1 \%)$, respectively. Resistance against the two pyrethroids may be due the over expression of the enzymes P450 mono-oxigenases [41], whilst resistance to carbamates may be to an elevated production of acetylcholinesterase [27]. Prior to undertaking this study, there was no previous report about the susceptibility status of malaria vectors from Balama district. However, results from this study contrast with that obtained in 2006 by Casimiro et al. [16] in Pemba city, located at approximately $250 \mathrm{~km}$ from Balama district, which reported full susceptibility ( $100 \%$ of mortality) of $A$. funestus to lambdacyalothrin $(0.05 \%)$, deltamethrin $(0.05 \%)$, propoxur (0.1\%), malathion (5\%) and DDT (4\%). The authors also detected an elevated expression of glutathione-Stransferase (GST) in the wild population of A. funestus compared to laboratory-resistant Aedes aegypti strains. As such, the resistance to DDT found in Balama district may probably be related to elevated expression of GST associated with resistance to DDT in several insect populations, including malaria vectors [27]. Recently, it has been demonstrated that a single mutation (GSTe2) in the sequence of the gene that encodes for GST in A. funestus from Benin, can confer resistance to both DDT and pyrethroids [42]. Previous studies from Southern Mozambique have also reported a high level of pyrethroid resistance in A. funestus [13] consistently associated with a high expression of cytochrome $\mathrm{P} 450$ mono-oxygenases [43, 44]. Unfortunately, in Mocuba city, the number of $A$. funestus collected was not enough to perform susceptibility tests, other than those used for the cone bioassay. Meanwhile, approximately 500 larvae of A. gambiae were collect. Adults derived from these larvae were used to perform the susceptibility tests (Fig. 2b; Table 2). Results indicate that $A$. gambiae from Mocuba city remains susceptible to bendiocarb $(0.1 \%)$, propoxur $(0.1 \%)$ and deltamethrin $(0.05 \%)$ but is possibly resistant to permethrin $(0.75 \%)$ and DDT $(4 \%)$. These findings contrast with those from Abilio and colleagues [15], who, in 2011, reported full susceptibility of $A$. gambiae s.l. to pyrethroids and DDT.

There were no $k d r$ gene resistant mutants detected in a random sample of $\mathrm{n}=256 \mathrm{~A}$. gambiae tested, despite the susceptibility tests suggesting resistance to DDT and pyrethroids. The $k d r$ resistance mechanism has been consistently associated with cross-resistance to pyrethroid 


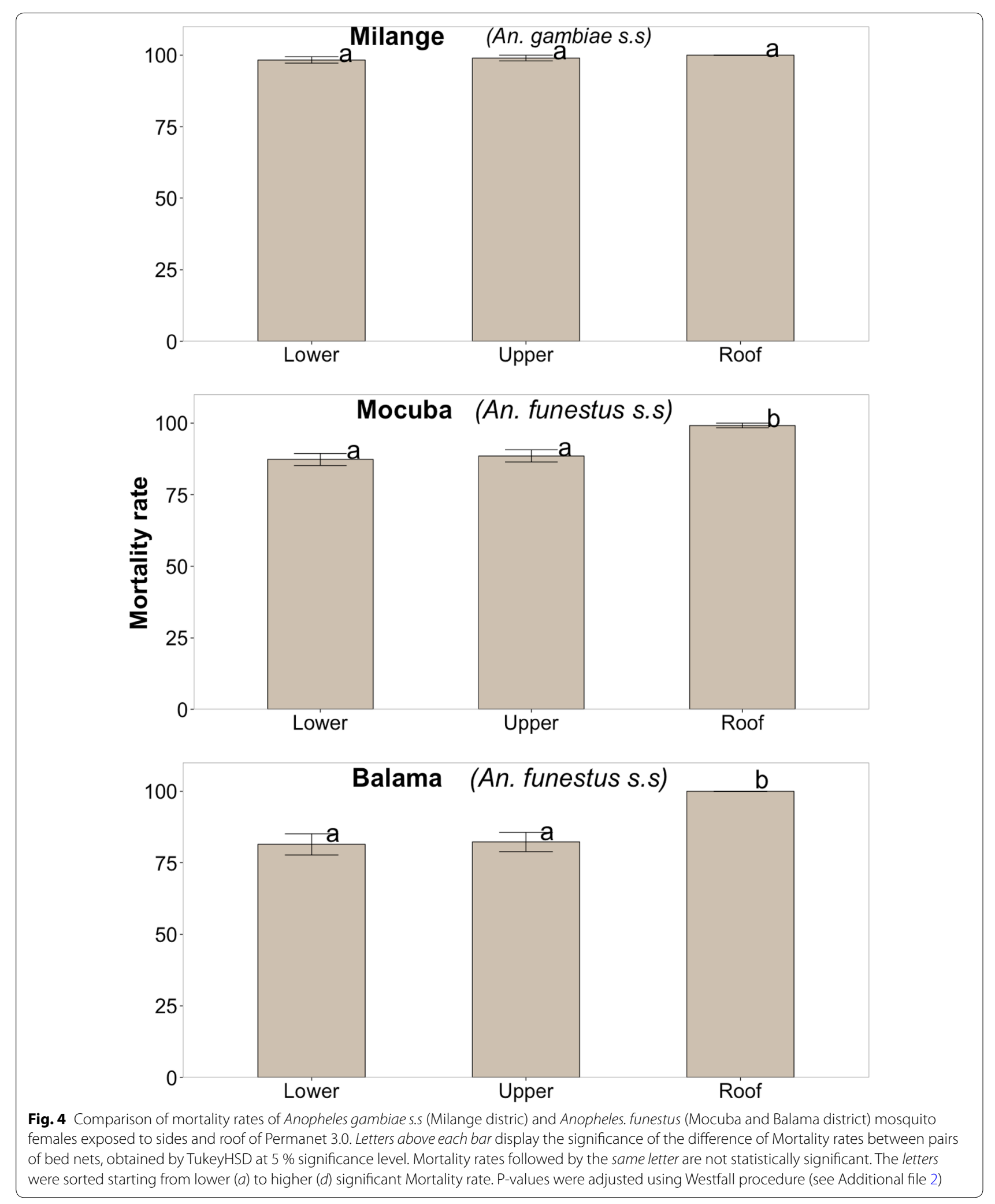


Table 4 Knockdown ( \pm standard error) and mortality ( \pm standard error) rates of $A$. funestus (Balama and Mocuba district) and A. gambiae s. from Milange district exposed to different sides of combination LLIN Permanet 3.0

\begin{tabular}{|c|c|c|c|c|c|}
\hline \multirow[t]{2}{*}{ Permanet 3.0 sides } & \multirow{2}{*}{$\begin{array}{l}\text { Mosquito tested } \\
\text { per site }\end{array}$} & \multirow[t]{2}{*}{ Bio-efficacy indexes } & \multicolumn{3}{|l|}{ Study sites } \\
\hline & & & Balama ( $A$. funestus) & Mocuba (A. funestus) & Milange (A.gambiae) \\
\hline \multirow[t]{2}{*}{ Lower side (border) } & 240 & KD 60 (土se) & $90( \pm 2.06)$ & $84.58( \pm 1.91)$ & $100( \pm 0.00)$ \\
\hline & & Mortality rate ( \pm se) & $81.46( \pm 3.69)$ & $87.29( \pm 2.10)$ & $98.33( \pm 1.15)$ \\
\hline \multirow[t]{2}{*}{ Upper side } & 240 & KD 60 (土se) & $93.33( \pm 1.92)$ & $80( \pm 2.60)$ & $99( \pm 1)$ \\
\hline & & Mortality rate ( \pm se) & $82.29( \pm 3.35)$ & $88.54( \pm 2.13)$ & $99( \pm 1)$ \\
\hline \multirow[t]{2}{*}{ Roof } & 120 & KD 60 ( \pm se) & $100( \pm 0.00)$ & $96.67( \pm 1.55)$ & $100( \pm 0.00)$ \\
\hline & & Mortality rate $( \pm$ se) & $100( \pm 0.00)$ & $99.17( \pm 0.83)$ & $100( \pm 0.00)$ \\
\hline
\end{tabular}

Highlighted cell indicates where significant difference between knockdown and mortality rate of vector was found at $5 \%$ significance level

Table 5 Knockdown ( \pm standard error) and mortality rates ( \pm standard error) of insectary-susceptible $A$. arabiensis (Durban strain) exposed to LLINs

\begin{tabular}{lllr}
\hline Type of LLIN & $\begin{array}{l}\text { Mosquito } \\
\text { tested }\end{array}$ & KD 60 \pm se & \multicolumn{1}{c}{$\begin{array}{l}\text { Mortality } \\
\text { rate } \pm \text { se }\end{array}$} \\
\hline Olyset & 360 & $68.33 \pm 2.26$ & $90.36 \pm 1.35$ \\
Permanet 2.0 & 360 & $94.72 \pm 1.12$ & $100 \pm 0.00$ \\
Permanet 3.0 & 600 & $98.17 \pm 0.58$ & $100 \pm 0.00$ \\
NetProtect & 360 & $83.89 \pm 1.80$ & $99.44 \pm 0.39$ \\
Interceptor & 360 & $80.56 \pm 1.63$ & $98.84 \pm 0.57$ \\
\hline
\end{tabular}

and DDT in populations of A. gambiae and A. arabiensis [27]. The mechanism is yet to be identified in $A$. funestus [28]. Unfortunately, metabolic resistance assays were not carried out in this study. Therefore the insecticide resistance mechanism involved in conferring resistance among these insects is not known yet. Riveron et al. [42] have recently reported that a single amino acid change in the binding pocket of the glutathione-s-transferase epsilon 2 (GSTe2) gene confers a high level of DDT resistance and also cross-resistance to pyrethroids in A. funestus. The expression of GSTe 2 mutation has also been widely documented in A. gambiae [45].

\section{Bio-efficacy of pyrethroid-only LLINs}

This study is the first to determine the response of wild-caught malaria vectors from Central (Mocuba and Milange districts) and Northern (Balama district) regions of Mozambique to commonly available types of LLINs. The results of cone bioassay indicated that the bio-efficacy of pyrethroid-only LLINs varied significantly depending on the vectors species tested (Fig. 3; Additional file 1). Overall, Olyset ${ }^{\circledR}$ and NetProtect ${ }^{\circledR}$ showed a dramatically lower bio-efficacy, regardless of vector species was tested (Table 3 ). Permanent $2.0^{\circledR}$ showed a higher bio-efficacy against both $A$. funestus from Balama and Mocuba city and against $A$. gambiae from Milange district, compared to either Olyset ${ }^{\circledR}$ or NetProtect ${ }^{\circledR}$.

Table 6 Comparisons between measured and target dose of insecticide contents on swatches from sides and roof of LLINs

\begin{tabular}{|c|c|c|c|c|c|c|}
\hline Net type & Active ingredient & Net section & $\begin{array}{l}\text { Target mean } \\
\text { dose }\end{array}$ & $\begin{array}{l}\text { Target dose } \\
\text { range }\end{array}$ & $\begin{array}{l}\text { Measured } \\
\text { mean dose }\end{array}$ & $\begin{array}{l}\text { Measured dose } \\
\text { within product } \\
\text { target range? }\end{array}$ \\
\hline \multirow[t]{2}{*}{ Interceptor (IT) } & Alpha-cypermethrin & Roof & $200 \mathrm{mg} / \mathrm{m}^{2}$ & $150.0-250.0$ & $204.2 \mathrm{mg} / \mathrm{m}^{2}$ & Yes \\
\hline & Alpha-cypermethrin & Sides & $200 \mathrm{mg} / \mathrm{m}^{2}$ & $150.0-250.0$ & $204.2 \mathrm{mg} / \mathrm{m}^{2}$ & Yes \\
\hline \multirow[t]{2}{*}{ NetProtect (NP) } & Deltamethrin & Roof & $1.8 \mathrm{~g} / \mathrm{kg}$ & $1.35-2.25$ & $1.0 \mathrm{~g} / \mathrm{kg}$ & Under \\
\hline & Deltamethrin & Sides & $1.8 \mathrm{~g} / \mathrm{kg}$ & $1.35-2.25$ & $1.0 \mathrm{~g} / \mathrm{kg}$ & Under \\
\hline \multirow[t]{2}{*}{ Olyset (OL) } & Permethrin & Roof & $20 \mathrm{~g} / \mathrm{kg}$ & $17.0-23.0$ & $23.2 \mathrm{~g} / \mathrm{kg}$ & Over \\
\hline & Permethrin & Sides & $20 \mathrm{~g} / \mathrm{kg}$ & $17.0-23.0$ & $23.6 \mathrm{~g} / \mathrm{kg}$ & Over \\
\hline \multirow[t]{2}{*}{ Permanet 2.0 (PN2) } & Deltamethrin & Roof & $55 \mathrm{mg} / \mathrm{m}^{2}$ & $41.25-68.75$ & $73.2 \mathrm{mg} / \mathrm{m}^{2}$ & Over \\
\hline & Deltamethrin & Sides & $55 \mathrm{mg} / \mathrm{m}^{2}$ & $41.25-68.75$ & $65.8 \mathrm{mg} / \mathrm{m}^{2}$ & Yes \\
\hline \multirow[t]{4}{*}{ Permanet 3.0 (PN3) } & Deltamethrin & Roof & $4 \mathrm{~g} / \mathrm{kg}$ & $3.0-5.0$ & $3.4 \mathrm{~g} / \mathrm{kg}$ & Yes \\
\hline & Deltamethrin & Lower side (border) & $2.8 \mathrm{~g} / \mathrm{kg}$ & $2.1-3.5$ & $3.0 \mathrm{~g} / \mathrm{kg}$ & Yes \\
\hline & Deltamethrin & Upper side & $2.8 \mathrm{~g} / \mathrm{kg}$ & $2.1-3.5$ & $3.1 \mathrm{~g} / \mathrm{kg}$ & Yes \\
\hline & PBO & Roof & $25 \mathrm{~g} / \mathrm{kg}$ & $18.75-31.25$ & $28.8 \mathrm{~g} / \mathrm{kg}$ & Yes \\
\hline
\end{tabular}


However, in Balama district Permanet $2.0^{\circledR}$ had a lower bio-efficacy compared to that observed in Mocuba and Milange districts (Table 3). The lower performance of these two type of pyrethroid-only LLINs, particularly against $A$. funestus from Balama district, may be due to the existence of resistant individuals in the local vector population as demonstrated in the WHO susceptibility tests (Fig. 2a; Tables 1, 2). Olyset ${ }^{\circledR}$ and Permanet $2.0^{\circledR}$ have been the two main brands of LLINs usually distributed as part of mass and antenatal distribution campaigns in Mozambique. Thus, results from Balama district strongly suggest that Olyset ${ }^{\circledR}$ and Permanet $2.0^{\circledR}$ may not be effectively killing $A$. funestus in those regions where there are resistant population foci. Studies should be extended to other locations of Balama district in order to get the current picture on both phenotypic and metabolic insecticide resistance profile in the malaria vectors population and, thereby, be able to accurately predict the impact any control approach may have on the vector populations at district level. However, several studies have shown that LLINs still protect people against infectious mosquito bites despite insecticide resistance detected in the vector population, since the pyrethroids are also, to certain degree, repellent to mosquitoes [46] and, as long as the integrity of the fabric remains intact, the LLIN is also a physical barrier between sleepers and mosquitoes, [47]. In addition, more than $90 \%$ of susceptible $A$. arabiensis were killed when exposed to LLINs in bioassays (Table 5; Additional file 3), suggesting that the LLINs can control susceptible mosquitoes. Interestingly, the mortality rate of A. gambiae from Milange exposed to both Interceptor ${ }^{\circledR}$ and NetProtect ${ }^{\circledR}$ was statistically similar $(P=0.839)$ (see Table 3; Fig. 3; Additional file 1$)$; this suggest that the two types of LLINs might probably perform equally well in the field. Since they have been treated with different insecticide formulations then having both nets in use may reduce the selective pressures that favour the occurrence of resistant strains in the vector compared to the situation when a single type of insecticide or LLINs is used. Unfortunately, the bio-efficacy of Interceptor ${ }^{\circledR}$ against vectors from Balama and Mocuba was not assessed. However, the knockdown and mortality rate of A. funestus from Furvela village, in southern Mozambique, exposed to Interceptor ${ }^{\circledR}$ swatches, suggested that the vector population was resistant to the insecticide (JD Charlwood et al., unpublished report).

\section{Bio-efficacy of combination Permanet $3.0^{\circledR}$}

Permanet $3.0^{\circledR}$ performed well against the two malaria vectors populations, irrespective of the level of resistance to pyrethroids. Anopheles funestus from Balama and Mocuba district exposed to swatches from the roof had the highest mortality compared to mosquitoes exposed to the upper and lower sides of the net whilst the mortality rates of $A$. gambiae from Milange district was independent of the location tested (Table 4; Fig. 4; Additional file 2). The higher mortality rates observed when mosquitoes were exposed to roofing swatches of Permanet 3.0 ${ }^{\circledR}$ was probably due to the presence of the synergist $\mathrm{PBO}$ and the higher concentration of insecticide on the fabric of the roof of the net. In southern Mozambique, Brooke and colleagues [13] managed to revert the resistance of $A$. funestus against the lambda-cyalothrin after preexposing the insect to $\mathrm{PBO}$. This prompted the authors to suspect that the mean metabolic resistance involved at the time (in 2001) was the over expression of enzyme mono-oxygenases; later reported in A. funestus from Belulane district [43] and recently in A. funestus from Chókwè villages [44]. The higher concentration of deltamethrin in the roofing fabrics compared to sides of Permanet $3.0^{\circledR}$ may have also caused higher mortality rate of mosquitoes exposed to it. However, increased insecticides concentration may be, per se, a counterproductive measure, since it can also contribute to rapid selection of resistant strains in the population, as discussed in [48]. Previous and recent field and laboratory works have reported better performance of combinations of "two-inone" approaches, i.e. the combination of pyrethroid and non-pyrethroid insecticides applied to different parts of the bed nets [49]. However, recent reports have demonstrated that the better performance of Permanet $3.0^{\circledR}$ has been only achieved with unwashed bed nets $[50,51]$. These studies have also noted that the biological activity of both deltamethrin and PBO tend to reduce significantly after a few washes, despite a high concentration of the two insecticidal compounds [52], suggesting that further investigation on insecticide retention by Permanet $3.0^{\circledR}$ fabrics must be done to improve the field performance of the net.

\section{Insecticide concentration on bed nets}

Chemical analysis of swatches from the sides and roof of the nets indicated that the insecticide content from the sides and roof of Olyset ${ }^{\circledR}$ and the roof of Permanet $2.0^{\circledR}$ was above the target dose. On the other hand, the insecticide concentration of NetProtect ${ }^{\circledR}$ was below that recommended dosage (Table 6). Intriguingly, Olyset ${ }^{\circledR}$ showed a low performed against both vectors species despite high level of insecticide found. This implies that different types of insecticide resistance mechanisms are involved. Laboratory and field evidence has shown that the insecticide concentration on the fabric of a LLIN decays over time, for instance after 6 months of intensive usage and washes, as recently reported in Permanet $3.0^{\circledR}$ [51] or due to bad storage. However, in the present study new nets were tested. The integrity of the packets and the expiration 
date of each type of LLIN were carefully verified before the extraction of the sub-samples. Therefore, the low insecticide content observed in NetProtect ${ }^{\circledR}$ swatches was caused by unidentified factors. Similar studies have reported significant differences of insecticide contents between the sides and roof of Permanet $2.0^{\circledR}[5]$ and Permanet $3.0^{\circledR}$ [53]. These findings have obvious operational implications since the concurrent exposure of vectors to varying doses of the same insecticides might potentiate resistance in the vector [6].

All types of LLINs tested in this study performed remarkably very well against the colony of susceptible $A$. arabiensis, maintained at the insectary of the National Institute of Health (INS) in Maputo.

\section{Conclusion}

Considerable heterogeneity in both, insecticide susceptibility and the level of bio-efficacy of commonly available types of LLIN's was observed among pyrethroid resistant populations of wild-caught $A$. funestus and A. gambiae from northern and central Mozambique. The findings suggest that vector control approaches by combining different types of pyrethroid-based methods, particularly LLINs, might help to tackle the apparent problem of pyrethroid resistance in the malaria vectors such as these, as it would both increase the killing efficacy against the vectors and concurrently reduce the selective pressures favouring the occurrence of resistant strains. The on-going management of insecticide resistance in vector control programmes is, obviously, mandatory for an effective malaria control. Results from bioassays against susceptible $A$. arabiensis strongly suggested the LLINs tested will still kill susceptible mosquitoes and so can help reduce transmission. Similar studies should be extended throughout the country in order to fill the gaps in the current knowledge concerning the status of phenotypic and metabolic resistance of malaria vectors populations, as well as, to determine the extent to which vectors might respond to insecticide-based vector control approaches prior to their implementation.

\section{Additional files}

Additional file 1: Results of pair-wise comparisons, obtained by TukeyHSD test, of overall mortality rates of mosquitoes exposed to different types of LLINs.

Additional file 2: Results of pair-wise comparisons, obtained by TukeyHSD, of mortality rates of mosquitoes exposed to different sides of Permanet 3.0.

Additional file 3: Ratio between the mortality rate of insectary-susceptible Anopheles arabiensis (Durban strain) and the mortality rate of wildcaught Anopheles funestus (from Balama, Mocuba district) and Anopheles gambiae s.s. from Milange district. The figure shows that the LLINs can still remarkably killing higher number (mortality rate $>90 \%$ ) of susceptible mosquitoes.

\section{Authors' contributions}

APA conceived the study, helped write the protocol, co-ordinated and supervised the field work and drafted the manuscript; PM, helped coordinate and supervise the field work in Cabo Delgado Province; ND and FM, helped with the preparation of field work, co-ordination, logistics/material/reagents; PM helped coordinate and supervise field work in Zambézia Province and reviewed the manuscript; AK, helped design the study, write the protocol, coordinated and supervised the field work, analysed the data and wrote the final manuscript. All authors read and approved the final manuscript.

\section{Author details}

${ }^{1}$ Laboratório de Entomologia, Instituto Nacional de Saúde (INS), Av. Eduardo Mondlane/Salvador Allende, no 1008, C.P. 246 Maputo, Mozambique. ${ }^{2}$ Programa Nacional de Controlo da Malária (PNCM), Direcção Provincial de Saúde de Cabo Delgado, Cabo Delgado Province, Mozambique. ${ }^{3}$ Departamento de Pesquisa, Instituto Nacional de Saúde (INS), Av. Eduardo Mondlane/Salvador Allende, no 1008, C.P. 246 Maputo, Mozambique. ${ }^{4}$ Direcção Nacional de Saúde Pública (DNSP), Av. Eduardo Mondlane/Salvador Allende, no 1008, C.P. 246 Maputo, Mozambique. ${ }^{5}$ Abt Associates Inc/AIRS, Zambezia Province, Mozambique.

\section{Acknowledgements}

The authors thank the people from Milange, Mocuba and Balama districts for their co-operation during the fieldwork. Thanks are due to also the Entomology technicians of the Laboratory of Entomology (INS), particularly: Julio Matusse, Elias Machoe, Jacinta Luciano and Samira Sibindy for their invaluable help during the field and laboratory work. Thanks are also due to the technical personnel from the Insectaries of the National Malaria Control Programmes at Cabo Delgado and Zambézia provinces. Two anonymous reviewers and J. Derek Charlwood gave helpful suggestions to improve the manuscript. The study received support from Vestergaard Frandsen and the Mozambique Ministry of Health. The funding Institutions did not have any role on the study design, data collection, analysis or decision to publish the study results.

\section{Compliance with ethical guidelines}

\section{Competing interests}

The authors declared that they have no competing interests.

Received: 24 June 2015 Accepted: 3 September 2015

Published online: 17 September 2015

\section{References}

1. Snow RW, Lindsay SW, Hayes RJ, Greenwood BM. Permethrin-treated bed nets (mosquito nets) prevent malaria in Gambian children. Trans R Soc Trop Med Hyg. 1988;82:838-42.

2. Strode C, Donegan S, Garner P, Enayati AA, Hemingway J. The impact of pyrethroid resistance on the efficacy of insecticide-treated bed nets against African anopheline mosquitoes: systematic review and metaanalysis. PLoS Med. 2014;11:e1001619.

3. Millennium Development Goal (MDG) 6: Combat HIV/AIDS and other diseases. http://www.mz.one.in.org.

4. Programa Nacional de Controlo da Malária. Plano Estratégico da Malária. Maputo: Ministério da Saúde, República de Moçambique; 2012.

5. Norris LC, Norris DE. Efficacy of long-lasting insecticidal nets in use in Macha, Zambia, against the local Anopheles arabiensis population. Malar J. 2011;10:254.

6. Mouchet J. Mini review: agriculture and vector resistance. Insect Sci Appl. 1988:9:297-302.

7. Diabaté A, Baldet T, Chandre F, Akogbeto M, Guiguemde TR, Darriet F, et al. The role of agricultural use of insecticides in resistance to pyrethroids in Anopheles gambiae s.l. in Burkina Faso. Am J Trop Med Hyg. 2002;67:617-22.

8. Thompson R, Begtrup K, Cuamba N, Dgedge M, Mendis C, GamageMendis A, et al. The Matola malaria project: a temporal and spatial study of malaria transmission and disease in a suburban area of Maputo, Mozambique. Am J Trop Med Hyg. 1997;57:550-9. 
9. Mendis C, Jacobsen JL, Gamage-Mendis A, Bule E, Dgedge M, Thompson $\mathrm{R}$, et al. Anopheles arabiensis and An. funestus are equally important vectors of malaria in Matola coastal suburb of Maputo, southern Mozambique. Med Vet Entomol. 2000;14:171-80.

10. Charlwood JD, Cuamba N, Tomas EV, Briet OJ. Living on the edge: a longitudinal study of Anopheles funestus in an isolated area of Mozambique. Malar J. 2013;12:208.

11. Charlwood JD, Macia GA, Manhaca M, Sousa B, Cuamba N, Braganca M. Population dynamics and spatial structure of human-biting mosquitoes, inside and outside of houses, in the Chockwe irrigation scheme, southern Mozambique. Geospat Health. 2013;7:309-20.

12. Cuamba N, Mendis C. The role of Anopheles merus in malaria transmission in an area of southern Mozambique. J Vector Borne Dis. 2009;46:157-9.

13. Brooke BD, Kloke G, Hunt RH, Koekemoer LL, Temu EA, Taylor ME, et al. Bioassay and biochemical analyses of insecticide resistance in southern African Anopheles funestus (Diptera: culicidae). Bull Entomol Res. 2001;91:265-72

14. Casimiro S, Coleman M, Mohloai P, Hemingway J, Sharp B. Insecticide resistance in Anopheles funestus (Diptera: culicidae) from Mozambique. J Med Entomol. 2006;43:267-75.

15. Abilio AP, Kleinschmidt I, Rehman AM, Cuamba N, Ramdeen V, Mthembu DS, et al. The emergence of insecticide resistance in central Mozambique and potential threat to the successful indoor residual spraying malaria control programme. Malar J. 2011;10:110.

16. Casimiro S, Coleman M, Hemingway J, Sharp B. Insecticide resistance in Anopheles arabiensis and Anopheles gambiae from Mozambique. J Med Entomol. 2006;43:276-82.

17. WHO. Global plan for insecticide resistance management in malaria vectors. World Health Organization, Geneva, WHO Press; 2012.

18. The spatial distribution of Plasmodium falciparum malaria stratified by endemicity class map in 2010 in Mozambique. http://www.map.ox.ac.uk/ explore/countries/MOZ/\#!malaria-risk.

19. Giardina F, Kasasa S, Sie A, Utzinger J, Tanner M, Vounatsou P. Effects of vector-control interventions on changes in risk of malaria parasitaemia in sub-Saharan Africa: a spatial and temporal analysis. Lancet Glob Health. 2014;2:e601-15

20. WHO. Manual on pratical entomology in malaria. Part II: Methods and Techniques. Geneva: World Health Organization; 1975.

21. Gillies MT, De Meillon B. The Anophelinae of the Africa south of the sahara (Ethiopian zoographical region). South Africa: South African Institute for Medical Research; 1968.

22. Koekemoer LL, Kamau L, Hunt RH, Coetzee M. A cocktail polymerase chain reaction assay to identify members of the Anopheles funestus (Diptera: Culicidae) group. Am J Trop Med Hyg. 2002;66:804-11.

23. Scott JA, Brogdon WG, Collins FH. Identification of single specimens of the Anopheles gambiae complex by the polymerase chain reaction. Am J Trop Med Hyg. 1993;49:520-9.

24. WHO. Test procedures for insecticide resistance monitoring in malaria vectors, bio-efficacy and persistence of insecticide on treated surfaces. Geneva: World Health Organization; 1998.

25. Martinez-Torres D, Chandre F, Williamson MS, Darriet F, Berge JB, Devonshire AL, et al. Molecular characterization of pyrethroid knockdown resistance $(\mathrm{kdr})$ in the major malaria vector Anopheles gambiae s.s. Insect Mol Biol. 1998;7:179-84.

26. Ranson H, Jensen B, Vulule JM, Wang X, Hemingway J, Collins FH. Identification of a point mutation in the voltage-gated sodium channel gene of Kenyan Anopheles gambiae associated with resistance to DDT and pyrethroids. Insect Mol Biol. 2000;9:491-7.

27. Hemingway J, Ranson $\mathrm{H}$. Insecticide resistance in insect vectors of human disease. Annu Rev Entomol. 2000;45:371-91.

28. Bass C, Nikou D, Donnelly MJ, Williamson MS, Ranson H, Ball A, et al. Detection of knockdown resistance $(\mathrm{kdr})$ mutations in Anopheles gambiae: a comparison of two new high-throughput assays with existing methods. Malar J. 2007:6:111.

29. Permanet 3.0 Brochure. http://www.vestergaard.com/permanet-3-0.

30. Technical basis for deployment of PermanetNet 3.0 in areas with pyrethroid-resistant malaria vectors. http://www.vestergaard.com/images/ pdf/PN3_Tech_Eng_2015.pdf.

31. Moores GD, Bingham G. Use of "temporal synergism" to overcome insecticide resistance. Outlook Pest Manag. 2005;16:7-9.
32. WHO. Guidelines for laboratory and field testing of long-lasting insecticidal mosquito nets. Geneva: World Health Organization; 2005.

33. Ouattara JP, Pigeon O, Spanoghe P. Validation of a multi-residue method to determine deltamethrin and alpha-cypermethrin in mosquito nets by gas chromatography with electron capture detection (GC-muECD). Parasit Vectors. 2013;6:77.

34. Collaborative International Pesticides Analytical Council (CIPA). http:// www.cipac.org/cipacpub.htm.

35. Jenkins DW, Hensens A, Lloyd J, Payne M, Cizmarik P, Hamel S. Development and validation of a 'universal'HPLC method for pyrethroid quantification in long-lasting insecticidal mosquito nets for malaria control and prevention. Trop Med Int Health. 2013;18:2-11.

36. Bolker BM, Brooks ME, Clark CJ, Geange SW, Poulsen JR, Stevens MH, et al. Generalized linear mixed models: a practical guide for ecology and evolution. Trends Ecol Evol. 2009;24:127-35.

37. Bates D, Maechler M, Bolder B, Walker S. Ime4: Linear mixed-effects models using Eigen and S4 (arXiv 2014, 1406:5823v1).

38. Hothorn T, Bretz F, Westfall P. Simultaneous inference in general parametric models. Biometrical J. 2008;50:346-63.

39. Bretz F, Hothorn T, Westfall P: Multiple Comparison Using R. Chapman \& Hall/CRC; 2010.

40. R Core Team. A language and environment for statistical computing Vienna: R Foundation for Statistical, Computing; 2015

41. Feyereisen R. Insect P450 enzymes. Annu Rev Entomol. 1999;44:507-33.

42. Riveron JM, Yunta C, Ibrahim SS, Djouaka R, Irving H, Menze BD, et al. A single mutation in the GSTe2 gene allows tracking of metabolically based insecticide resistance in a major malaria vector. Genome Biol. 2014;15:R27.

43. Amenya DA, Naguran R, Lo TC, Ranson H, Spillings BL, Wood OR, Brooke BD, et al. Over expression of a cytochrome P450 (CYP6P9) in a major African malaria vector, Anopheles funestus, resistant to pyrethroids. Insect Mol Biol. 2008;17:19-25.

44. Cuamba N, Morgan JC, Irving H, Steven A, Wondji CS. High level of pyrethroid resistance in an Anopheles funestus population of the Chokwe District in Mozambique. PLoS One. 2010;5:e11010.

45. Hemingway J. The molecular basis of two contrasting metabolic mechanisms of insecticide resistance. Insect Biochem Mol Biol. 2000;30:1009-15.

46. N'Guessan R, Darriet F, Doannio JM, Chandre F, Carnevale P. Olyset net efficacy against pyrethroid-resistant Anopheles gambiae and Culex quinquefasciatus after 3 years field use in Cote d'Ivoire. Med Vet Entomol. 2001;15:97-104.

47. D'Alessandro U, Olaleye BO, McGuire W, Thomson MC, Langerock P, Bennett $S$, et al. A comparison of the efficacy of insecticide-treated and untreated bed nets in preventing malaria in Gambian children. Trans $R$ Soc Trop Med Hyg. 1995;89:596-8.

48. Prevention and Management of Insecticide Resistance in Vectors of Public Heath Importance. http://www.irac-online.org/documents/ irm-vector-manual/?ext=pdf.

49. Guillet P, N'Guessan R, Darriet F, Traore-Lamizana M, Chandre F, Carnevale P. Combined pyrethroid and carbamate 'two-in-one' treated mosquito nets: field efficacy against pyrethroid-resistant Anopheles gambiae and Culex quinquefasciatus. Med Vet Entomol. 2001;15:105-12.

50. Koudou BG, Koffi AA, Malone D, Hemingway J. Efficacy of PermaNet(R) 2.0 and PermaNet(R) 3.0 against insecticide-resistant Anopheles gambiae in experimental huts in Cote d'Ivoire. Malar J. 2011;10:172

51. Awolola ST, Adeogun AO, Olojede JB, Oduola AO, Oyewole IO, Amajoh CN. Impact of PermaNet 3.0 on entomological indices in an area of pyrethroid resistant Anopheles gambiae in south-western Nigeria. Parasit Vectors. 2014;7:236.

52. WHO. Report of the Twelfth WHOPES Working Group Meeting. Geneva: World Health Organization; 2009.

53. Okia M, Ndyomugyenyi R, Kirunda J, Byaruhanga A, Adibaku S, et al. Bioefficacy of long-lasting insecticidal nets against pyrethroid-resistant populations of Anopheles gambiae s.s. from different malaria transmission zones in Uganda. Parasit Vectors. 2013;6:130. 